Study of the issues arising in the community care of discharged hospital patients should help clarify the planning, preparation and support services for those in-patients who will be resettled into the community in the future.

Meanwood Park Hospital

DOuglas A. SPENCER

Leeds LS6 4QB

\section{Discharge delays}

\section{DeAR SirS}

We report a recently completed study which examined discharge delays from the acute admission wards of a psychiatric hospital once the psychiatric condition for which the patient was admitted had been dealt with. In addition to the waste of resources implied, it raises questions on the ways in which this could affect the cost, quality of service, and patients' satisfaction about their care.

We conducted a questionnaire survey on four acute admission wards for the under $65 \mathrm{~s}$ and three acute admission wards for the over $65 \mathrm{~s}$, over three months.

Sixty-six patients ( 30 under 65 s and 36 over 65 s) were identified to have spent extra time in hospital for non clinical reasons and the extra time spent by them was 3,727 days with an average of 49.7 days for under $65 \mathrm{~s}$ and 62.1 days for the over $65 \mathrm{~s}$. During the 91 day study period, of the total 15,117 bed occupancy positions on the seven wards, 2,768 $(18 \%)$ were occupied by patients awaiting discharge, despite being ready to leave hospital.

Of the various reasons for delays in discharge, accommodation problems ranked highest, with $73 \%$ $(22 / 30)$ of under 65 s falling in this group. Among the psychogeriatric patients, the accommodation problem was the sole cause of delay in only $11 \%$ (4/36); however, when those awaiting Part 111 accommodation $(12 / 36)$ were also included, the figure rose to $44 \%(16 / 36)$. The second important factor was internal transfer to continuing care wards in the case of over $65 \mathrm{~s}(25 \%)$ and to rehabilitation wards for the under $65 \mathrm{~s}$. Although the proportion of patients in this category was less than those awaiting accommodation, the average length of extra time spent per person was substantially higher (122.2 days v. 36.8 days).

Legal problem (section 37/41) was causing delay in discharge in one patient (under 65) who had already spent an extra 108 days at the close of the study. Other reasons included awaiting transfer to other facilities (e.g. medical wards, reprovision programme) within and outside the health authority and those awaiting input from social services.

Our findings confirm the considerable problem posed for treatment teams by discharge delays, leading to occupancy of facilities in acute admission wards which are then unavailable for other patients who may require them. In the present climate of thinly spread resources, this limits the availability of acute beds which are already insufficient to meet the demands of the respective catchment areas. The implications of this waste of limited clinical resources are serious. The reasons for delayed discharge seem to point to major accommodation problems in the community and it emerges that there is a need to increase these resources. It may also be worthwhile to consider the provision of a 'Resettlement Officer' to liaise with the community and co-ordinate the effective use of available facilities. More detailed analysis should be undertaken in future, attempting to find out whether diagnostic categories have any influence in delays, staff attitudes in hospital and in other agencies, especially for patients with prolonged or multiple admissions. Findings of the present audit will be distributed to Social Services, Housing Agencies and Unit General Management, to help improve deficiencies in the existing services. The authors wish to repeat this audit on a regular basis to monitor any change in trends. A more systematic study may be required to focus on the exact nature of the difficulties in the context of available local resources. This will help plan future mental health services in the area.

University College and

V. EAPEN

Middlesex School of Medicine

London WIN 8AA

Claybury Hospital

L. FAGIN

Woodford Green

Essex $1 G 88 B Y$

\section{Out of hours admission}

DeAr SirS

We read with interest Gardner's study of out of hours admissions to a general psychiatric hospital (Psychiatric Bulletin, 1992, 16, 357-358). The nature and volume of such admissions have important implications for staffing levels and service planning. When assessing their volume it is important to take into account the timing of the preceding referral.

Not all patients admitted out of hours have been referred out of hours. We wonder whether the author has data on the proportion of out of hours admissions in which the decision to admit was made during routine hours. Due to differences in working hours, duty rota and shift systems of medical and nursing staff, the time of referral is likely to be of greater importance to doctors, and the time of admission more important to nursing staff. Out of hours, medical staffing levels are reduced to a skeleton on-call team, and it is this team that is called upon to make the decision whether or not to admit a 
referred patient. Factors independent of diagnosis can affect the time of admission, for example, distance from the hospital. In our study of observation levels of acute psychiatric admissions (Langenbach et al, 1992), we found that the number of admissions varied with the day of the week. Of the 88 admissions during the one month study period, there was a peak of $20(23 \%)$ on Fridays and a trough of six $(7 \%)$ on Sundays.

The proportion of referrals later admitted will be affected by the assessment procedure employed and the organisation of the psychiatric services. Tyrer et al (1989) described the significant reduction in psychiatric admission rates in Nottingham with the establishment of a comprehensive rehabilitation service in 1980, and the introduction of a sectorised service in 1981. It is important to remember the role of senior medical staff and domiciliary visits in the assessment procedure, as a way of reducing inappropriate admissions.

As psychiatry continues to become more community orientated and the number of in-patient beds is reduced, it becomes increasingly important to avoid inappropriate admissions. This is an area which deserves further study.

Christine M. Hodgson

Queen's Medical Centre

Nottingham NG7 2UH

\section{References}

Langenbach, M., Moorhead, S., Ruiz, P., Hodgson, C. et al (1992) Observation levels in acute psychiatric admission. Annual Meeting of Royal College of Psychiatrists.

TYRER, P., TURnER, R. \& Johnson, A. L. (1989) Integrated hospital and community psychiatric services and use of inpatient beds. British Medical Journal, 299, 298-300.

\section{Management of anxiety \\ DeAr Sirs}

In their guidelines for the management of patients with generalised anxiety (Psychiatric Bulletin, 1992, $16,560-565$ ), the members of the consensus conference exclude hypnosis from their list of recognised psychological therapies. This seems a strange omission.

Relaxation, which is included in the recognised list of therapies, occurs also in eye fixation and progressive muscle relaxation, a commonly used method of induction and deepening in clinical hypnosis.

This differs from the Jacobson method of relaxation (Jacobson, 1938) cited by the authors, not only in technique but also in the much greater variety of suggestions used to achieve a state of complete calm. Not uncommonly, patients who have experienced the two methods report a better and more satisfying quality of relaxation from hypnosis. The latter has the added advantage over the Jacobson method in the shorter time taken to achieve complete relaxation and the ease with which patients can be taught to relax using self-hypnosis.

I am not aware of any intensive scientific scrutiny to which the Jacobson or any other method of relaxation has been subjected, as the authors suggest. Perhaps hypnosis offers no more and no less a 'complementary' method of relaxation than others and ought to be included in any 'recognised' list of anxiolytic psychological therapies.

The authors go on to imply that provision of psychological therapies depends on the availability of trained clinical psychologists, nurse behaviour therapists, community psychiatric nurses, and counselling services. Why is the psychiatrist omitted from this list? Every psychiatrist ought to be proficient in and able to offer at least one form of psychotherapy to his patients. The alternative is psychiatry offering an assessment service and biological treatment only with the bulk of specialised psychotherapy provided by non-medical therapists.

Judging from surveys, the general public expects psychiatry to offer psychotherapy as a form of treatment-biological therapy on its own is not enough.

Perhaps this dichotomy is reflected in the differing terminology used to describe the consumer in this paper. The main body of the text on description and management of anxiety refers only to 'patients', a term traditionally used by doctors and psychiatrists. The details of psychological therapies, however, almost entirely refer to the consumer as a 'client'. This unfortunate term conveys none of the complexity, suffering and endurance of patients (Regius, 1988); a patient is always a client but a client not always a patient.

Hellesdon Hospital

P. D. O'BRIEN

Norwich NR6 5BE

\section{References}

Jacobson, E. (1938) Progressive Relaxation. Chicago: Chicago University Press.

REgIUS, M.-C. (1988) A tale of two chairs. British Journal of Psychotherapy, 4, 282-293.

\section{Overseas trainees}

DEAR SIRS,

I read with interest Dr Adeniran's article (Psychiatric Bulletin, 1992, 16, 701-702) outlining his successful assimilation on the Overseas Doctors' Training Scheme, particularly after the recent correspondence highlighting problems for overseas trainees. 